\title{
Los usuarios como base para el desarrollo de colecciones: la biblioteca pública
}

$\mathrm{L}$ as necesidades de información son un elemento central de la teoría bibliotecológica, puesto que las actividades bibliotecarias y de información se sustentan en satisfacer las necesidades que tienen las personas que asisten, por ejemplo, a la biblioteca pública y que comúnmente llamamos usuarios.

De acuerdo con Rendón Rojas, ${ }^{1}$ en la relación informaciónsoporte de la información-usuario-documento-unidad de información, las necesidades de información del usuario se relacionan con la actividad bibliotecaria correspondiente al desarrollo de colecciones que lleva a cabo la unidad de información, con la finalidad de satisfacer las necesidades de la comunidad a la cual atiende. Determinar y satisfacer las necesidades de información puede ser considerado, entonces, como uno de los propósitos básicos de las unidades de información, llámense bibliotecas públicas, hemerotecas, centros de documentación, centros de información, etcétera. Por tanto, una necesidad de información corresponde a la insuficiencia o carencia de conocimiento acerca de algunos objetos o de partes de esos objetos, fenómenos o hechos que, para ser subsanada, requiere de conocimiento adicional. $^{2}$

Por lo anterior, no hay que perder de vista que la información la genera el ser humano y la registra en algún soporte con miras a su posterior utilización por otras personas en diferente

1 Miguel Ángel Rendón Rojas, Bases teóricas y filosóficas de la bibliotecología, México: UNAM, Centro Universitario de Investigaciones Bibliotecológicas, 1997, p. 123.

2 El concepto de necesidades de información se trata en Juan José Calva González, Las necesidades de información. Teoría y métodos, México: UNAM, 2001, p. 76. 
tiempo. Las personas necesitan poseer cierta información y conocimiento que les permitan orientarse en el mundo y actuar de manera congruente con él; ambos han sido desarrollados a lo largo del proceso histórico y les proporcionarán las posibilidades de adaptarse al medio y de transformarlo, ya que esto es una característica intrínseca a los seres humanos. La información y los conocimientos se obtienen, entre otras actividades, con la ayuda de la actividad bibliotecaria. ${ }^{3}$

La información y el conocimiento insuficientes sobre algún objeto, fenómeno o hecho producen una insatisfacción en la persona e impulsan a que aparezca una necesidad de información, con el propósito de comprender en su totalidad ese fenómeno, hecho u objeto. Se puede afirmar que las necesidades de información son un fenómeno que se repite en nuestra sociedad actual infinidad de veces y que aparece en las personas como entes individuales o cuando están reunidas en grupo, por ejemplo, en las organizaciones.

Las comunidades de sujetos se encuentran ligadas con las funciones y los miembros de la sociedad: el comercio, los médicos, los hospitales, los abogados, los despachos jurídicos, las docentes y alumnos, las escuelas, los obreros, las fábricas, las amas de casa, los hogares, los contadores, los despachos contables, etcétera. Los diversos sectores sociales se vinculan con las bibliotecas públicas puesto que, con el fin de lograr un avance social, es preciso que la sociedad se encuentre informada, ya que la información es un factor importante para el progreso de los ciudadanos y para alcanzar los objetivos sociales, económicos y políticos de un país. ${ }^{4}$ Las personas integrantes de estos sectores sociales requieren de apoyo informativo para desempeñar eficientemente su actividad, otorgado por la biblioteca pública. Para que cumpla con este objetivo existen diversos sistemas bibliotecarios; por ejemplo, en México se cuenta con la Red Nacional de Bibliotecas Públicas. Es necesario que cada biblioteca pública conozca las necesidades de información de su comunidad.

Cabe señalar que las obras que tratan sobre las necesidades de información de los sectores sociales que rodean a la biblioteca pública son aún escasas, lo que comprueba que todavía no

3 Rendón Rojas, op. cit., p. 40.

4 Elsa Barberena, Las necesidades de información en eláreacientifica, México: [s. 1.], [s. a.], p. 6. 
se sabe con certeza cómo se resuelven las necesidades de información ${ }^{5}$ ni cuáles son éstas. Por ello se requieren estudios o investigaciones sobre las necesidades de información de sectores sociales con respecto a la biblioteca pública, en el contexto de México y otros países.

El surgimiento y manifestación de las necesidades de información de los diversos sectores sociales pueden estar influidos por diversos factores, entre ellos:

- Lugar donde habitan.

- Los objetivos, funciones y rol que tienen dentro de su sector social.

- Área de actividad (comercio, salud, hacienda, etc.).

- Tema de interés en ese momento (influenza, elecciones, sismos, clima, narcotráfico, seguridad, etc.).

- Tipo de actividad a la que se dedican (comerciante, abogado, médico, estudiante, docente, obrero, ama de casa, gestor, etc.).

- Apoyos para realizar sus actividades cotidianas.

- Conocimientos y experiencia en el tema o área de su competencia (contabilidad, medicina, ventas, etc.).

- Experiencia en el uso de recursos de información (biblioteca pública, Internet, etc.).

- Uso de los recursos y fuentes informativas para obtener la información que necesitan, así como acceso a las diversas unidades de información.

Es necesario identificar las necesidades de información de la comunidad que debe atender una biblioteca pública, lo cual es posible a partir de tener un perfil completo de tal comunidad. La identificación de las necesidades de información de los usuarios puede ubicarse en torno de tres tipos: sobre un autor (ej. Carlos Fuentes), sobre un asunto o problema (ej. seguridad social) o sobre un tema concreto (ej. tratamiento para la influenza AH1N1). Es posible que los tres tipos estén presentes al mismo tiempo en la necesidad informativa de un usuario de la biblioteca pública.

5 Pablo Velásquez, Las necesidades de los usuarios de la información agrícola en América Latina, Buenos Aires: [s. n.], 1972, p. 5. 
Las bibliotecas públicas, al contar con un perfil de sus usuarios o de la comunidad de ciudadanos, podrán determinar qué necesidades de información tienen y con base en ello desarrollar la colección documental que las satisfaga (libros, revistas, videos, documentos electrónicos, etc.). Esto concuerda con lo mencionado por Negrete: "[...] el desarrollo de colecciones tiene como objetivo construir una colección de materiales documentales, cuyo contenido responda con efectividad a las necesidades de información de la comunidad a la que sirve". ${ }^{6}$

En suma, la investigación sobre las necesidades de información de algún sector social que atienda la biblioteca pública puede tener como base lo siguiente para el desarrollo de colecciones:

- Los diversos sectores sociales tienen necesidades de información, las cuales se manifestarán a través de un comportamiento informativo para buscar la información que las satisfaga.

- El surgimiento de las necesidades de información de las comunidades está influido por diversos factores internos y externos, los cuales tienen gran movilidad.

- Al pasar el tiempo surgirán nuevas necesidades de información, ya sea originadas por las que ya han sido satisfechas o completamente nuevas.

- Los sujetos que integran los diversos sectores sociales pueden presentar tres tipos de necesidades de información simultáneas.

- La biblioteca pública debe encargarse de identificar las necesidades de información de su comunidad mediante el uso de diferentes métodos; a partir de los resultados que obtenga es como desarrollará sus colecciones.

- Las necesidades de información dentro de la relación información-usuario-soporte donde está registrada la información-unidad de información son la base para el desarrollo de colecciones. Lo anterior implica que

6 María del Carmen Negrete Gutiérrez. La selección de materiales en el desarrollo de colecciones. -México: UNAM. Centro Universitario de Investigación Bibliotecológica. 1997. p. 23. 
las unidades de información contarán con el acceso a la información registrada en algún documento impreso o electrónico.

Juan José Calva González 